Asian Journal of Computer Science and Technology

ISSN: 2249-0701 Vol.7 No.S1, 2018, pp. 78-81

(C) The Research Publication, www.trp.org.in

\title{
A Relative Study of Various Routing Protocols in Mobile Ad Hoc Network
}

\author{
R. Anandha Lakshmi ${ }^{1}$ and T.Suresh ${ }^{2}$ \\ ${ }^{1}$ Research Scholar \& Assistant Professor, Anna Adarsh College for Women, Chennai, Tamil Nadu, India \\ ${ }^{2}$ Assistant Professor, Department of Computer Science \& Engineering, \\ Annamalai University, Annamalai Nagar, Tamil Nadu, India \\ E-Mail: anandhalakshmi.sk@gmail.com
}

\begin{abstract}
Mobile Ad hoc Network (MANET) is an infrastructure fewer networksbuilt on a multihop conveying idea. It transmits data from base node to end node. Because MANETS don't have any fixed infrastructure and it works in a distributed manner. For efficient communication, many routing protocols are used in MANET. Routing protocols are to find a new route to transmit data from base to accurate endthrough the midway nodes. Every in-between node is act as a router. So, this paper is covers the routing protocols AODV, DSR, DSDV and OLSR to keepcurrent routing information from every node to each other nodes. The purpose of this paper to offers a relative study of routing protocols in MANETand energy aware performance metrics are analyzed on two routing protocols of AODV and DSDV.

Keywords: MANET, AODV, DSR, DSDV, OLSR
\end{abstract}

\section{INTRODUCTION}

Wireless network is an equipment that permits two or more computers to join without network cable. The structure of MANET is shown in Fig.1.The wireless networks are classified into two categories.

1. Infrastructure network

2. Infrastructure-less network

MANET is a collection of mobile nodes and also infrastructure-less network. In MANET [3], nodes can move easily and it can also communicate with different nodes at any time. In infrastructure wireless networks, the base stations are fixed. If the node goes out the series of a base station, it gets into the series of another base station. All the nodes in the network act as routers and as a host. There are no exact routers, servers, access pointers and act as fast and cool to arrangement, strength, and low price. Wireless networks offer more flexibility and adjust easily to fluctuations in the structure of the network.

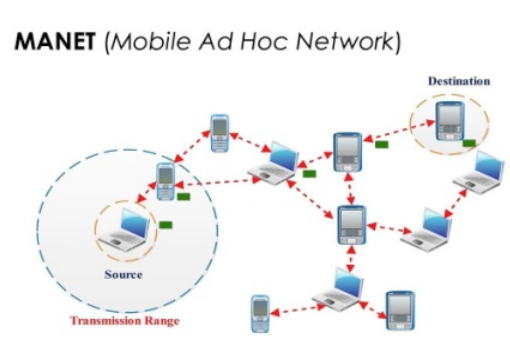

Fig. 1 Mobile Ad-hoc Network
Energy conservation in MANET is a vital because the limited energy offered in each wireless node. In wireless network, the communication between two nodes consumes more energy. It is important to reduce the cost of energy by employing an energy conscious routing method. The rest of the paper is structured as follows Section 2 describes the various Routing Protocols in MANET. The Section 3 consists of the Simulation and Experimental outcomes conducted and finally the Section 4 concludes the paper.

\section{ROUTING PROTOCOLS}

To convey a packet from base to endthrough in-between nodes a routing protocol is needed. For MANET many routing protocols have been planned. During packetdelivery these Protocols find a route from base to accurate end. For this reasons the routing protocols can be used:

1. Discover a path

2. Select an optimal path

In Direction-finding, each node discovers the nearest node and finds an optimal route to reach it. After that packet transmission will occur. Routing protocols are mainly classified into two types is shown in Fig.2. [1]

1. Table driven protocols

2. $\quad$ On-demand protocols

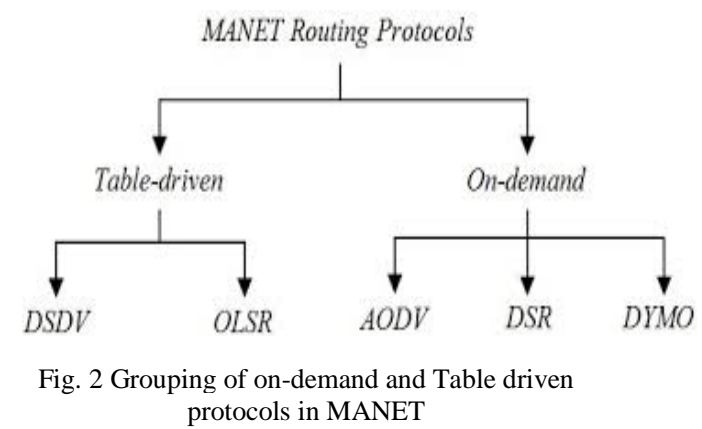

\section{A. On-Demand Routing Protocols}

On Demand Routing Protocols, where the paths are not predefined for direction-finding. Each node in this protocol maintains a data of all the active nodes in the route to destination. For each new destination, route search is 
required. So that it decrease the delay of expense. This protocol establishes a path to anend on demand. The path discovery mechanism is built on flooding algorithm. It is themethod that a node just broadcasts the packet to all of its neighbors. In-between nodes just forward that packet to their neighbors. This protocol has greater potential and lesser routing overheads as compared to Table driven protocols. Example: DSR, AODV.

1. Ad-hoc On-demand Distance Vector (AODV): AODV is an On-demand routing protocol is shown in Fig.3. It is a distance vector protocol. In distance vector algorithm, each node keeps the distance of all destinations. AODV it stores all the available routes for known destination using the distance route algorithm. The source sends RREQ to the neighbor nodes. Then the neighbors send the RREQ to all its intermediary nodes which in the network to realize a new routes. RREQ (Routing Request) contains source code IP address, Source code current sequence number, destination code sequence number and broadcast ID. AODV protocols are used to catch the greatest and shortest path. Advantage of AODV is that it doesn't take extra traffic communication but it takes extra time for establishing a new connection.

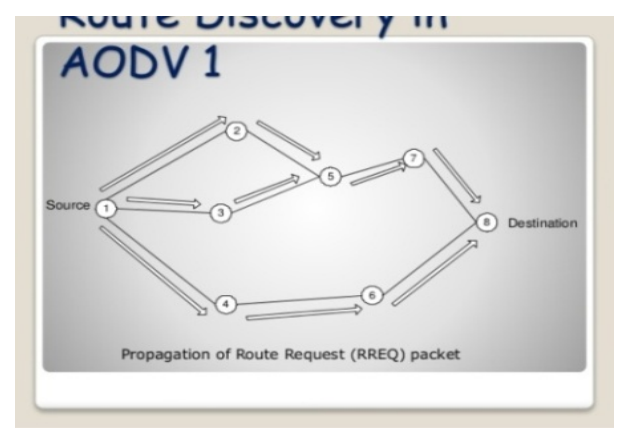

Fig. 3 Ad hoc On-demand Distance Vector

2. Dynamic Source Routing (DSR): DSR is designed for multi-hop wireless networks of multiple nodes. So that it is called self organizing. DSR is also reactive routing protocol is shown in Fig.4. It is a distance vector protocol. In the route discovery process, sender finds the existing path to the destination in the cache. If the path exist it transmit the packets otherwise it will discover a new path. If the discover process takes time, the network is in in the shiftlessmethod. So the transmitter can achieve any other sending/receiving process. Then the revealed path introduced in the cache for upcoming use.

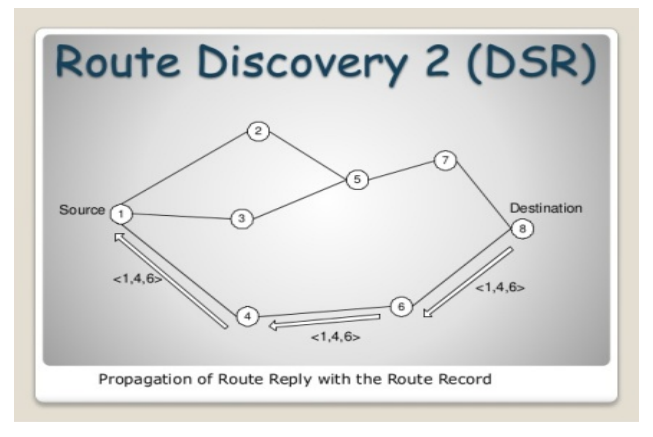

Fig. 4 Dynamic Source Routing

\section{A. Table Driven Protocols}

Table driven protocols are keeps and allocating routing tables through the entire network. It gathers information regularly with the neighbors [1]. So that it keeps up to date evidence about the neighbors.

\section{Destination Sequenced Distance Vector Routing Protocol (DSDV)}

It is a Table driven protocol in which each node has a leading table. In the leading table it has the separation of next node, number of jumps. DSDV, each node is essential to convey a sequence number. Sequence number isincreased by two frequently. It alsotransmits routing update messages to all neighboring nodes. The neighboring nodesreceive the update messages and choose whether to overlook the update or to make the required changes to its routing table based on the following algorithm [2]

1. S1: Receive the update message.

2. S2: If any one of the two conditions given below satisfies, then update the routing table: i) $S_{n}>S_{p}$ ii) $\mathrm{S}_{\mathrm{n}}=\mathrm{S}_{\mathrm{p}}$, Hop count is less Otherwise, overlook the update message. Where, $S_{n}$ is the sequence number of new message $\& S_{p}$ is the sequence number of existing message.

Advantage of DSDV is it is suitable for small number of nodes as shown in Fig.5.

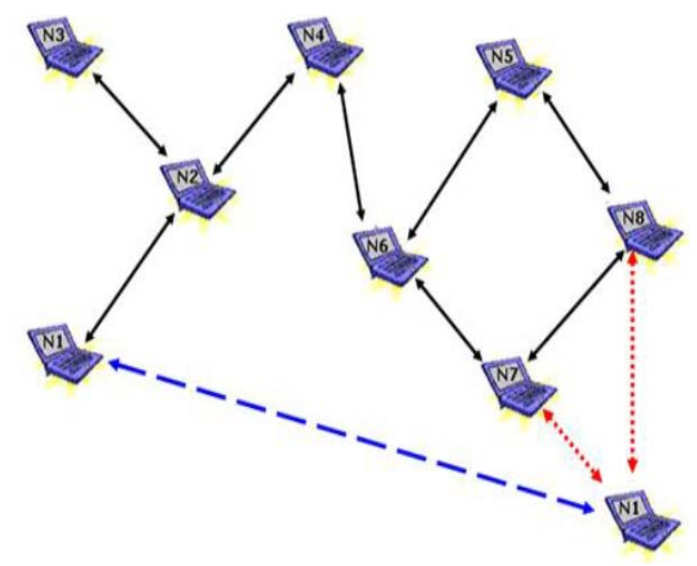

Fig.5 Dynamic Source Routing

\section{Optimized Link State Routing Protocol (OLSR)}

OLSR is an IP routing protocol as shown in Fig 6. It is mainly used for MANET. OLSR use HELLO and TC messages to keeps and then allocate link state information through the entire network. This protocol inherits the stability of the link state algorithm. Because of the proactive nature it is having the routes available immediately. OLSR minimizes the control traffic by using only selected nodes, called Multi-Point Relays (MPR), to retransmit control messages. 


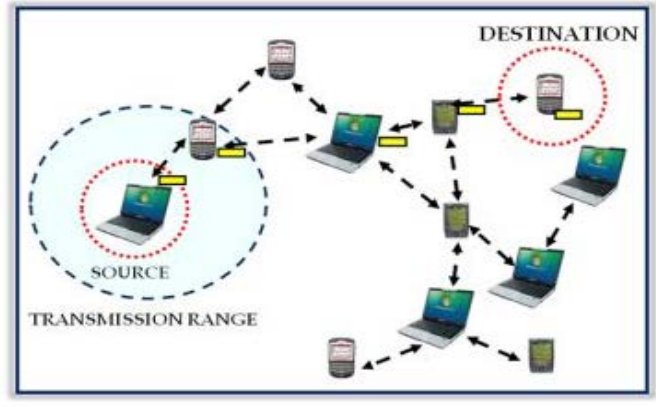

Fig. 5 Optimized Link State Routing Protocol

\section{Comparison of Table Driven and on-demand Routing} Protocols in MANET

In this paper four routing protocols are used for comparative study. It is selected based on the even routing protocol. In Even routing protocol, packets contains routing information was distributed to routers which are associated to each other without any subdivision structure between them. The comparison is given below in the Table I.

TABLE I COMPARISON OF DSDV, OLSR, AODV AND DSR

\begin{tabular}{|l|c|c|c|c|}
\hline \multicolumn{1}{|c|}{ Parameter } & DSDV & OLSR & AODV & DSR \\
\hline Routing Structure & Flat & Flat & Flat & Flat \\
\hline Route Acquisition Delay & Low & Low & High & High \\
\hline Control Overhead & Great & Great & Little & Moderate \\
\hline Loop Free & Surely & Surely & Surely & Surely \\
\hline Updates Transmitted to & Neighbor & Neighbor & Base & Base \\
\hline
\end{tabular}

\section{SIMULATION AND EXPERIMENTAL RESULTS}

During the transmission numbers of data packets are sending from source to destination.

TABLE II ENERGY CONSERVATION ANALYSIS PARAMETERS OF DSDV

\begin{tabular}{|c|c|c|c|c|}
\hline $\begin{array}{c}\text { No. of } \\
\text { Nodes }\end{array}$ & $\begin{array}{c}\text { Sent } \\
\text { Packets }\end{array}$ & $\begin{array}{c}\text { Received } \\
\text { Packets }\end{array}$ & $\begin{array}{c}\text { Remaining } \\
\text { Energy }\end{array}$ & $\begin{array}{c}\text { Consumed } \\
\text { Energy }\end{array}$ \\
\hline 5 & 2072 & 2060 & 136.12029 & 823.8797 \\
\hline 10 & 440 & 427 & 1021.9852 & 1938.0148 \\
\hline 25 & 3454 & 3438 & 4947.76086 & 4683.2393 \\
\hline 35 & 1961 & 1925 & 1098.2605 & 5861.7393 \\
\hline 45 & 2249 & 22468 & 800.5607 & 8159.4395 \\
\hline 55 & 3423 & 3389 & 518.13 & 10441.87 \\
\hline 65 & 4089 & 4076 & 89.43597 & 12870.564 \\
\hline 75 & 123 & 102 & 5802.0615 & 9157.938 \\
\hline 85 & 423 & 405 & 5264.9946 & 11695.006 \\
\hline 95 & 4003 & 3989 & 107.533585 & 18852.467 \\
\hline
\end{tabular}

TABLE III ENERgy CONSERVATION ANALYSIS PARAMETERS OF AODV

\begin{tabular}{|c|c|c|c|c|}
\hline $\begin{array}{c}\text { No. of } \\
\text { Nodes }\end{array}$ & $\begin{array}{c}\text { Sent } \\
\text { Packets }\end{array}$ & $\begin{array}{c}\text { Received } \\
\text { Packets }\end{array}$ & $\begin{array}{c}\text { Remaining } \\
\text { Energy }\end{array}$ & $\begin{array}{c}\text { Consumed } \\
\text { Energy }\end{array}$ \\
\hline 5 & 2092 & 2080 & 156.12029 & 843.8797 \\
\hline 10 & 460 & 447 & 1041.9852 & 1958.0148 \\
\hline 25 & 3474 & 3458 & 2967.76086 & 4703.2393 \\
\hline 35 & 1981 & 1945 & 1118.2605 & 5881.7393 \\
\hline 45 & 2269 & 22488 & 820.5607 & 8179.4395 \\
\hline 55 & 3443 & 3409 & 538.13 & 10461.87 \\
\hline 65 & 4109 & 4096 & 109.43597 & 12890.564 \\
\hline 75 & 143 & 122 & 5822.0615 & 9177.938 \\
\hline 85 & 443 & 425 & 5284.9946 & 11751.006 \\
\hline 95 & 4023 & 4009 & 127.533585 & 18872.467 \\
\hline
\end{tabular}

The entire number of data packets sent by the base within the simulation time is calculated. The following tables shows the energy conservation analysis parameters of different routing protocols [4]

\section{A. Experimental Results}

The following graphs show the performance Evaluation results of various routing protocols in MANET as shown in Fig. 7.The Experimental purpose, we have implemented NS-2 simulation.

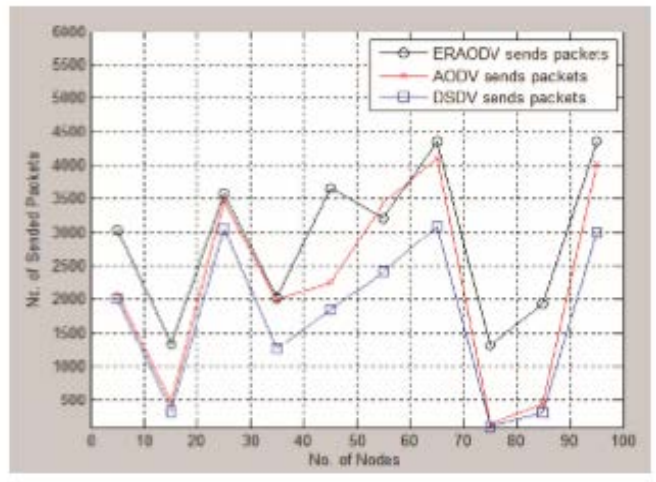

Fig. 7 The Performance Evaluation of various routing protocols in MANET

\section{CONCLUSION}

Routing protocols are deed as significantpart in MANETs. It is an importantidea of communication protocols in MANET. The AODV, DSR, DSDV, OLSR protocols created on important QoS parameters such as throughput, bandwidth, control overhead, routing structure, communication overhead etc. In future it may be extended to apply for WSN applications. 


\section{REFERENCES}

[1] Sameswari and E. Ramaraj, "Comparative study of AODV, DSR, DSDV and OLSR Routing Protocols in MANET", International Journal of Computer Applications, Vol. 21, No. 3, 2013.

[2] Jayanti and Vikram Nandal, "Routing Protocols in MANET: Comparative study ", International Journal of Computer Science and Mobile Computing, Vol. 2, No. 7, pp 117-125, 2014.
[3] Krishna and Goarntala, "Routing Protocols in Mobile Ad-hoc Networks”, International Journal of Computer Science and Mobile Computing, Vol. 4, No. 1, pp 159-167, 2016.

[4] B.S. Gowda, A. B Mandal and Lakshmi Narayana, "Simulation and Comparative analysis of Energy Conservation performance metric for ERAODV, AODV and DSDV routing Protocols in MANET", IEEE, Vol. 2, 2012.

[5] Neeraj Varma and Sarita Soni, "A Review of Different Protocols in MANET", International Journal of Advanced Research in Computer Science, Vol. 8, No. 3, 2017. 